\title{
Photochemical release of various functional groups*
}

\author{
Christian G. Bochet ${ }^{\ddagger}$ \\ Department of Chemistry, University of Fribourg, Chemin du Musée 9, CH-1700 \\ Fribourg, Switzerland
}

\begin{abstract}
The photochemical liberation of functional groups is an attractive alternative to the traditional chemical approach. Several photolabile protecting groups have been developed in the past decades, but they were mainly designed to protect amines and carboxylic acids. In this account, we present some of our recent work on the photochemical release of other functions, such as silanols, aldehydes, and ketones. We also describe a new form of differentiation among several photolabile groups by the use of monochromatic light tuned to each of them: the chromatic orthogonality.
\end{abstract}

Keywords: photochemistry; protecting groups; chromatic orthogonality.

\section{INTRODUCTION}

During the last few years, we have been active in investigating the possibility of selectively removing one among several protecting groups.

Whereas this operation constituted a real challenge in the last century, it has now become increasingly routine and predictable with the development of orthogonal protecting groups. Two groups are defined as orthogonal if one of them could selectively be removed in the presence of the other, and vice versa [1]. Figure 1 represents the reactivity of a protecting group under various chemical conditions (e.g., basic, acidic, or oxidizing). Ideally, a group should lie on one of the three orthogonal axes (hence, the term "orthogonality"), in order to react only under a very restricted set of conditions (e.g., only under acidic conditions).

In our approach, the orthogonal groups are all photolabile, and the specificity of their removal arises from the wavelength (i.e., the color) of a light beam. For this reason, we call this property chromatic orthogonality. In other words, the differentiation of various groups arises from the choice of the incident light [2]. With regard to Fig. 1, this means that the orthogonal variables (i.e., the chemical conditions depicted along the various axes) are replaced by wavelength domains $\left(v_{1}, v_{2}\right.$, and $\left.v_{3}\right)$.

\footnotetext{
*Pure Appl. Chem. 78, 197-523. An issue of reviews and research papers based on lectures presented at the $13^{\text {th }}$ IUPAC International Symposium on Organometallic Chemistry Directed Towards Organic Synthesis (OMCOS-13), Geneva, Switzerland, 17-21 July 2005.

¥Fax: +41-26-3009738; E-mail: Christian.Bochet@unifr.ch
} 


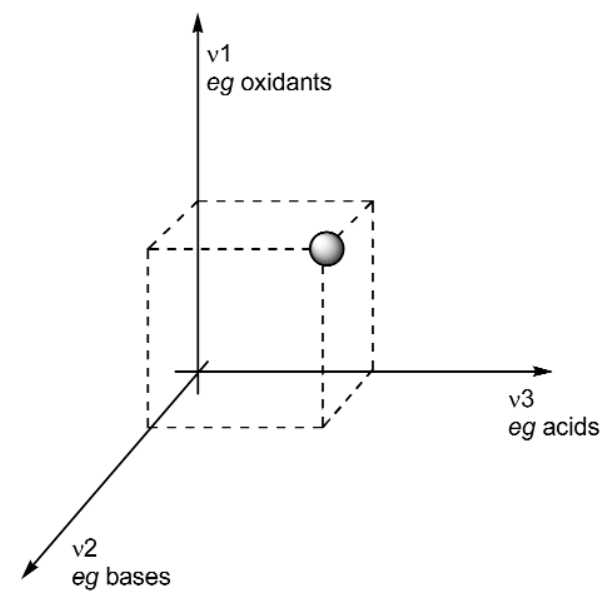

Fig. 1 Vectorial description of the reactivity of a protecting group.

\section{LIBERATION OF CARBOXYLIC ACIDS}

We have identified several pairs of chromatically orthogonal protecting groups, either among existing ones [3], or by designing new ones with properties tailored for our needs [4].

\section{Partial orthogonality: Solid-phase peptide synthesis}

A subset of orthogonality is called modulated lability [5], where one group can be removed in the presence of others, but not the reverse. This case is best exemplified by the family of silicon-based protecting groups, where a trimethylsilyl (TMS) ether can be hydrolyzed in the presence of a tert-butyldimethylsilyl ether, but never the other way around. In collaboration with the group of Bernd Giese at the University of Basel [6], we showed that the pivaloyl-derived photolabile group in Scheme 1 survives the relatively mild conditions (i.e., a wavelength of $350 \mathrm{~nm}$ ) needed to photolyze a nitroveratrylderived one. In a later step, more energetic light $(\lambda=305 \mathrm{~nm})$ is used to remove the pivaloyl group. However, the opposite sequence is not possible, because the nitroveratryl group is not stable to irradiation at $305 \mathrm{~nm}$.<smiles>COc1cc(COC(=O)CCCCCC(=O)OCC(C)(O)C(=O)C(C)(C)C)c([N+](=O)[O-])cc1OC</smiles>

1) hv $(350 \mathrm{~nm}) / \mathrm{THF}$ 2) $\mathrm{TMSCHN}_{2}$

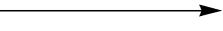

1) $\mathrm{hv}(305 \mathrm{~nm}) / \mathrm{THF}$
2) $\mathrm{TMSCHN}_{2}$<smiles>COC(=O)CCCCCC(=O)OC</smiles>

$99 \%$<smiles>COC(=O)CCCCCC(=O)OCC(C)(O)C(=O)C(C)(C)C</smiles><smiles>COC(=O)CCCCCC(=O)OC</smiles>

$2 \%$

Scheme 1 


\section{Complete orthogonality: Use of existing photolabile groups}

Complete chromatic orthogonality was found between the 3,5-dimethoxybenzoin group (254 nm) and the nitroveratryl group $(420 \mathrm{~nm})$, as exemplified by the photolysis of the diester in Scheme 2 where either step can be carried out before the other [3].

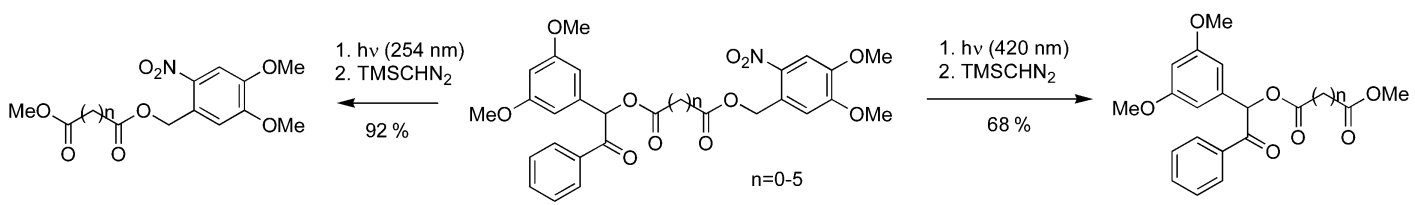

\section{Scheme 2}

\section{Complete orthogonality: Design of new groups}

In order to find additional orthogonal dimensions, we needed to have a deeper control on the reaction kinetics. As the overall observed reaction rate $\left(k_{\text {obs }}\right)$ depends on the chromophore's absorbance and the quantum yield for photocleavage, we wanted to fine-tune these parameters. The key step in the photochemical fragmentation of nitroveratryl alcohol esters is the abstraction of a benzylic hydrogen atom. Reasoning that there should be a significant H/D kinetic isotope effect, we prepared several deuterated analogs [4]. In some of them, the effect was sufficiently large $\left(k_{\mathrm{H}} / k_{\mathrm{D}}\right.$ up to 8$)$ to be synthetically exploited, as shown in Scheme 3. Thus, we achieved chromatic orthogonality between representatives of the same family of protecting groups.<smiles>[2H]C([2H])(OC(=O)CCCC(=O)OCc1cc(OC)c(OC)cc1[N+](=O)[O-])c1ccc(-c2ccccc2)cc1[N+](=O)[O-]</smiles>

1) hv (254 nm), $1 \mathrm{~h}$

2) $\mathrm{TMSCHN}_{2}$<smiles>C1CCCC1</smiles><smiles>COC(=O)CCCC(=O)OCc1cc(OC)c(OC)cc1[N+](=O)[O-]</smiles>

$61 \%$

1) hv $(350 \mathrm{~nm}), 4 \mathrm{~h}$

2) $\mathrm{TMSCHN}_{2}$ $85 \%$

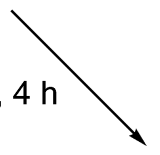<smiles>COC(=O)CCCC(=O)OC</smiles>

1) $\mathrm{hv}(419 \mathrm{~nm}), 40 \mathrm{~h}$

2) $\mathrm{TMSCHN}_{2}$<smiles>[2H]C([2H])(OC(=O)CCCC(=O)OC)c1ccc(-c2ccccc2)cc1[N+](=O)[O-]</smiles>

Scheme 3 


\section{LIBERATION OF CARBONYL GROUPS}

In the proof of principle shown above, we focused our attention on the liberation of carboxylic acids, masked (or "caged") as photolabile esters. The liberation of amines is relatively similar, since the photolysis of carbamates liberates a carbamic acid, prone to spontaneous (albeit sometimes slow) decarboxylation. However, in order to generalize our approach, we would have to address a larger set of functional groups, including carbonyl compounds, alcohols, thiols, silanols, etc. Here, we will discuss the photochemical liberation of ketones, aldehydes, and silanols.

\section{Liberation of ketone/aldehydes: Photolabile ketals/acetals}

The ketals of bis(o-nitrophenyl)ethanediol and ketones or aldehydes are smoothly deprotected under neutral conditions by irradiation with light of $350 \mathrm{~nm}$ (Scheme 4; PPTS = pyridinium $p$-toluenesulfonate). The chemical stability in basic, acidic, and oxidizing media makes this form of protection orthogonal to classical protecting groups. Both racemic and enantiopure forms are readily available in two steps from inexpensive starting materials [7].

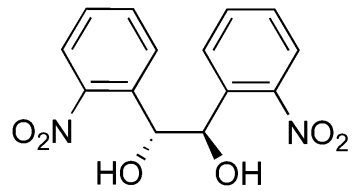<smiles>[R]C([R])=O</smiles>

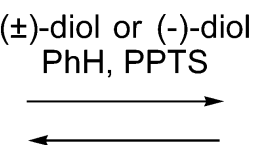

$\mathrm{h} v(350 \mathrm{~nm})$<smiles>[R]C1([R])OC(c2ccccc2[N+](=O)[O-])[C@H](c2ccccc2[N+](=O)[O-])O1</smiles>

Scheme 4

\section{Liberation of aldehydes: Photolabile $\alpha$-acetoxyethers}

Aldehydes and ketones are traditionally protected as acetals and ketals; the latter species offer good chemical resistance with respect to various conditions (basic, oxidizing, reducing, etc.). We have exploited this feature by introducing the bis-(o-nitrophenyl)ethane-1,2-diol. On the other hand, when stability in solution is not a central issue, $\alpha$-acetoxy ethers with their inherently simpler structure represent an attractive substitute to regular acetals, because their liberation is significantly less sensitive to the reaction medium (e.g., pH, water contents) (Scheme 5) [8].

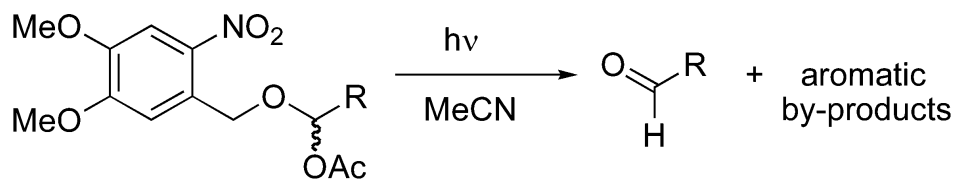

\section{Scheme 5}

\section{LIBERATION OF SILANOLS: PHOTOLABILE SILYL ETHERS}

Silyl ethers have been used as protecting groups for several decades, and their versatility and usefulness is documented in countless publications. In fact, none of the major total syntheses of complex natural products could have been achieved without silicon-based protecting groups. However, the attention is invariably focused on the organic residue (usually an alcohol) that is released upon deprotection and not on the silanol that is formed concomitantly. We turned our attention to the latter because the preparation of silanols, although well-documented [9], may suffer from problematic side-reactions, such as 
dimerization to disiloxanes [10]. If one could photochemically generate silanols in a completely neutral medium and in a time-controlled fashion, the problem of dimerization would be significantly diminished, and the silanols could be eventually used in situ. Hence, we reasoned that the standard photolysis of ortho-nitrobenzyl groups could be used to release silanols (Scheme 6):<smiles>COc1cc(CO)c([N+](=O)[O-])cc1OC</smiles><smiles>[R3][SiH3]C</smiles><smiles>[R][Si]([R])([R])OCc1cc(OC)c(OC)cc1[N+](=O)[O-]</smiles>

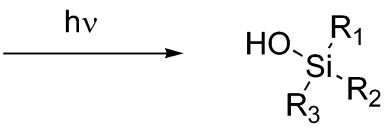

\section{Scheme 6}

For this purpose, we prepared a series of $o$-nitrobenzyl silyl ethers, with consistently high yields (60-97\%, see Table 1). As expected, their photolysis at $350 \mathrm{~nm}$ in acetonitrile (Rayonet ${ }^{\circledR}$ apparatus with RPR3500 lamps) smoothly released silanols, also in high yields (82-98 \%), without producing significant amounts of disiloxanes, at least as long as we did not try to isolate the silanols in substance. Hence, we determined the liberation yield by ${ }^{1} \mathrm{H}-\mathrm{NMR}$ with an internal standard, and by comparison with independently prepared reference samples.

\section{Table 1}

\begin{tabular}{llllll}
\hline Entry & $\mathrm{R}^{1}$ & \multicolumn{1}{c}{$\mathrm{R}^{2}$} & \multicolumn{1}{c}{$\mathrm{R}^{3}$} & Ether & Silanol \\
\hline 1 & $\mathrm{Me}$ & $\mathrm{Me}$ & $\mathrm{CH}=\mathrm{CH}_{2}$ & $86 \%$ & $90 \%$ \\
2 & $\mathrm{Me}$ & $\mathrm{Ph}$ & $\mathrm{Ph}$ & $88 \%$ & $98 \%$ \\
3 & $\mathrm{Me}$ & $\mathrm{Me}$ & $\mathrm{Me}$ & $97 \%$ & $98 \%$ \\
4 & $\mathrm{Me}$ & $\mathrm{C}_{18} \mathrm{H}_{37}$ & $\mathrm{Me}$ & $60 \%$ & $82 \%$ \\
5 & $\mathrm{Bn}$ & $\mathrm{Bn}$ & $\mathrm{Bn}$ & $90 \%$ & $86 \%$ \\
6 & $\mathrm{Me}$ & $\left(\mathrm{CH}_{2}\right)_{6} \mathrm{CH}=\mathrm{CH}_{2}$ & $\mathrm{Me}$ & $84 \%$ & $94 \%$ \\
7 & $n-\mathrm{Hex}$ & $n-\mathrm{Hex}$ & $n-\mathrm{Hex}$ & $73 \%$ & $92 \%$ \\
8 & $\mathrm{Ph}$ & $\mathrm{Ph}$ & $\mathrm{CH}=\mathrm{CH}_{2}$ & $71 \%$ & $97 \%$ \\
\hline
\end{tabular}

As mentioned earlier, this procedure is only useful if silanols are needed for in situ use, such as microlithography, but in organic synthesis this requirement is less obvious. From this perspective, entries 1 and 8 of Table 1 are remarkable, because the silanol is a vinyldialkylsilanol. Recently, Denmark et al. have published a series of studies showing the usefulness of vinylsilanols as a safe replacement for the toxic vinylstannanes in Pd-catalyzed cross-coupling reactions. In this approach, the silanol is deprotonated by a suitable base (sodium hydride or potassium trimethylsilanolate) and is reactive enough to undergo transmetallation with an arylpalladium halide, hence entering the typical catalytic cycle for cross-coupling reactions (Scheme 7) [11]. 


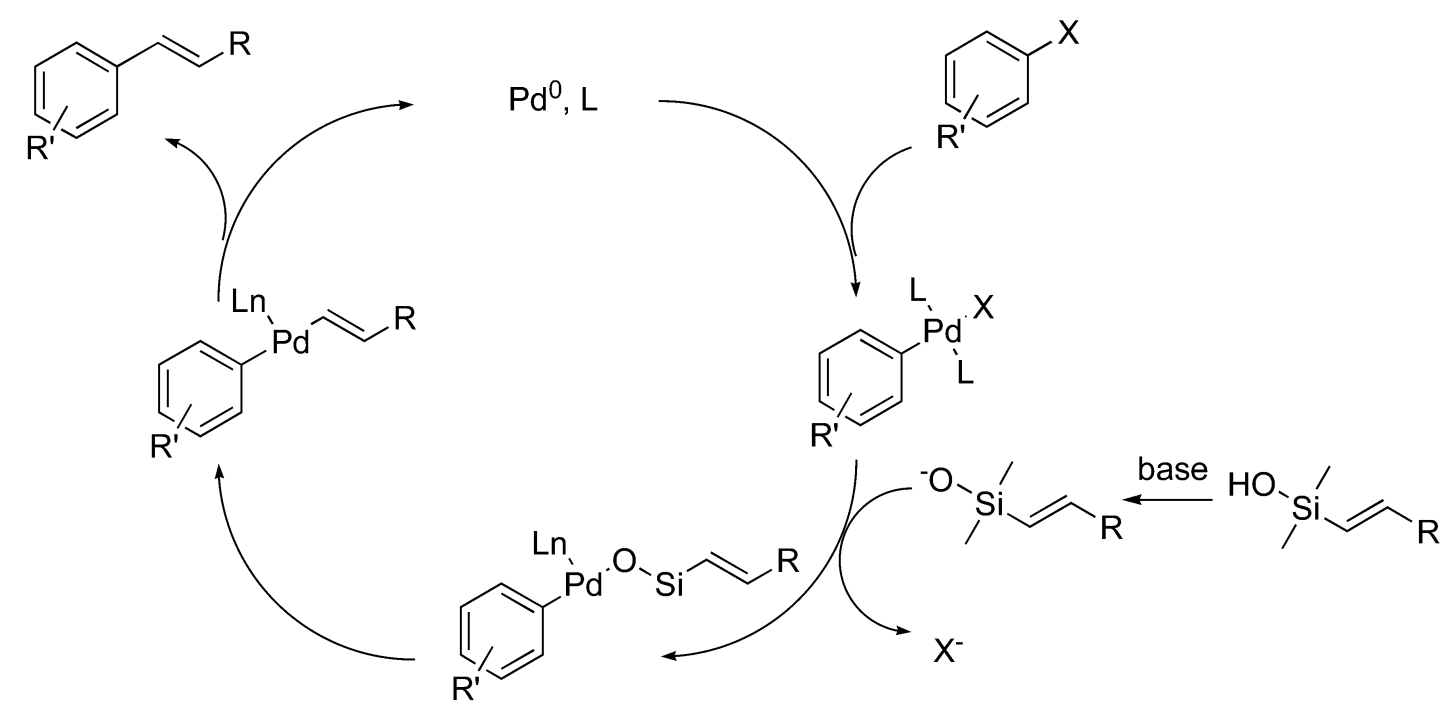

Scheme 7

Hence, we tried to plug our silanol photorelease method into this cycle. Our initial results were unsuccessful, because the photolabile silylethers were also chemically labile under the conditions developed by Denmark et al., and therefore the cross-coupling occurred also in the absence of light. Unfortunately, the base was really needed, as stated in the original publication, and by the failure of cross-coupling in the photolysis of dimethylvinylsilanol and $p$-nitroiodobenzene in the presence of a Pd-catalyst in strictly neutral medium. We then screened a series of bases and conditions. Although this project is still in the preliminary phase, we have found that our masked vinylsilanols can be coupled with $p$-nitroiodobenzene, by using tripotassium phosphate as a base and $\mathrm{Pd}_{2} \mathrm{dba}_{3}$ as a catalyst (yield up to $25 \%$; dba $=$ dibenzyildeneacetone) (Scheme 8).<smiles>[R]C=Cc1ccc([N+](=O)[O-])cc1</smiles>

Scheme 8

\section{CONCLUSION}

In conclusion, we have shown that the photochemical release of functional groups is not limited to the traditional carboxylic acids, ketones, or alcohols, but also to potentially more reactive groups, such as silanols. Since transition-metal-catalyzed processes are frequently part of cascade or domino reactions, precise control of the timing is critically important. Therefore, controlled release by an external triggering event is important, and we are continuing our efforts in this direction. 


\section{ACKNOWLEDGMENTS}

We thank our group of dedicated and talented coworkers who have made this work possible, in particular, Dr. Aurélien Blanc and Jaime Lage Robles. We are also grateful to the Swiss National Science Foundation (grant 620-066063) for their generous financial support.

\section{REFERENCES}

1. (a) R. B. Merrifield, G. Barany, W. L. Cosand, M. Engelhard, S. Mojsov. Pept., Proc. Am. Pept. Symp. $5^{\text {th }}, 488$ (1977); (b) C. G. Bochet. J. Chem. Soc., Perkin Trans. 1 125-152 (2002).

2. C. G. Bochet. Synlett 2268-2274 (2004).

3. (a) C. G. Bochet. Angew. Chem., Int. Ed. 40, 2071-2073 (2001); (b) A. Blanc and C. G. Bochet. J. Org. Chem. 67, 5567-5577 (2002).

4. A. Blanc and C. G. Bochet. J. Am. Chem. Soc. 126, 7174-7175 (2004).

5. M. Schelhaas and H. Waldmann. Angew. Chem., Int. Ed. 35, 2056-2083 (1996).

6. M. Kessler, R. Glatthar, B. Giese, C. G. Bochet. Org. Lett. 5, 1179-1181 (2003).

7. A. Blanc and C. G. Bochet. J. Org. Chem. 68, 1138-1141 (2003).

8. J. Lage Robles and C. G. Bochet. Org. Lett. 7, 3545-3547 (2005).

9. For a recent review, see: V. Chandrasekhar, R. Boomishankar, S. Nagendran. Chem. Rev. 104, 5847-5910 (2004).

10. P. D. Lickiss. Adv. Inorg. Chem. 42, 147-262 (1995).

11. (a) S. E. Denmark and R. F. Sweis. J. Am. Chem. Soc. 123, 6439 (2001); (b) S. E. Denmark and R. F. Sweis. J. Am. Chem. Soc. 126, 4876 (2004). 